\title{
Preface: The spatial dimensions of water management - Redistribution of benefits and risks
}

\author{
Andreas H. Schumann \\ Institute of Hydrology, Water Management and Environmental Engineering, Ruhr-University Bochum, \\ Bochum, 44780, Germany \\ Correspondence to: Andreas H. Schumann (andreas.schumann@rub.de) \\ Published: 12 May 2016
}

Many spatial aspects of hydrology and water management are discussed in these proceedings of the 7 th International Water Resources Management Conference of IAHS-ICWRS.

The main topics of the conference, specified in the call for papers, were:

1. Spatial aspects of water supply and the redistribution of benefits from water

2. Floods and spatial aspects of flood risks

3. Spatial aspects of water scarcity

4. Scale problems of water management - when the summation of individual measures becomes a problem

5. Hydrological regionalization issues

6. The spatial dimension in socio-hydrology

The response of the scientific community was very unevenly distributed. The most submissions were dedicated to the topics 2 and 4. Floods are hotspots of applied hydrology and so many different research questions were raised in these contributions, e.g. methods for design flood estimations, impact assessments and operational flood forecasting.

The second main component of the conference were hydrological regionalization issues. It became evident that after the completion of the PUB-Initiative of IAHS, which was summarized by Günter Blöschl at the conference, many research activities are still going on to transfer hydrologic information from gauged to ungauged basins by new methodological approaches.

Surprisingly, the "classical" fields of water management, water supply and water scarcity, were less represented. This could be caused by two reasons: there are some tools available which are widely used (e.g. stochastic optimization) but not further improved, or (and this seems to be more probable) there is a low interest to apply new scientific tools in practical water management to optimize existing systems or to improve the planning of new ones. Nevertheless very interesting and (in some cases) sophisticated methodological approaches were presented in this field at the conference under the topics 1, 3 and 4 .

With regard to future challenges of water research, the dynamic interactions and feedbacks between water and people becomes more and more important. One part of the conference was dedicated to these questions. Unfortunately the interesting presentations and discussions cannot be reflected completely in the proceedings. Nevertheless the participants got a comprehensive overview about the problems of sociohydrology and the need for interdisciplinary research.

This conference was organized the second time at the Ruhr-University Bochum. In September 2006 scientists from all over the world met in Bochum for the 3th IWRM Symposium. In that time the conference accounted for the heterogeneity of world water problems by addressing the basic questions of Integrated Water Resources Management. Now, ten years later, the coherence between surface and groundwater, water quality and quantity or water and ecosystems are widely accepted aspects of modern water management. However the differences between hydrological conditions and the human expectations are still in the focus of research. More and more we become aware that water management is not able to serve societies in the solution of their water problems in a sustainable way if interactions and feedbacks between hydrological conditions and societies are not considered.

The stationarity assumption has long been compromised by human disturbances in river basins. The dynamics of changing societies will face water management with new and unexpected problems. To give an example: If a water poor 
country like Jordan with 6 Million inhabitants host 1.5 Million refugees, the long-term planning of water management issues will be overtaken by operational constraints. I hope that we will be able to find ways to direct our research activities towards these new problems of a fast changing world. Conferences like this one can make a contribution in this direction. 